\title{
Granuloma faciale: a good therapeutic response with the use of topical tacrolimus*
}

\author{
Raquel Sucupira Andrade Lima ${ }^{1}$ \\ Renato Cândido da Silva Junior ${ }^{1}$ \\ Mônica Santos ${ }^{1,2}$
}

\author{
Gustavo Ávila Maquiné ${ }^{1}$ \\ Antonio Pedro Mendes Schettini ${ }^{1}$
}

DOI: http:/ /dx.doi.org/10.1590/abd1806-4841.20153339

\begin{abstract}
Granuloma faciale is a rare dermatosis of chronic course, benign, usually asymptomatic, first described in 1945 by Wingley. It is characterized by the appearance of well-defined, single or multiple papules, plaques and nodules, predominantly located in sun-exposed areas, especially the face. In this work we report the case of a female patient, 58 years old, evolving for ten years with multiple erythematous-brownish and asymptomatic papules on the face, whose histological examination confirmed the diagnosis of granuloma faciale. The patient was treated with topical tacrolimus, evolving with regression of lesions.
\end{abstract}

Keywords: Granuloma; Primary treatment; Tacrolimus; Therapeutics

\section{INTRODUCTION}

Granuloma faciale (GF) is a rare, idiopathic dermatosis, of benign course and chronic progression, that predominantly affects white middle-aged men. Clinically, it is manifested by the presence of erythematous-brownish papules, nodules or plaques, single or multiple, well-delimited and with a smooth surface, that may also present exacerbation of follicular orifices and telangiectasias. ${ }^{1}$ The face is the most involved site, but there are reports of extra facial and disseminated cases. The lesions are frequently asymptomatic and the patient may experience pruritus or a burning sensation. The diagnosis is confirmed through an histological examination where a mixed and dense cellular infiltrate, composed of lymphocytes, neutrophils, plasmocytes and eosinophils is evident, separated from the epidermis by a prominent Grenz zone. ${ }^{2}$ The infiltrate is predominantly perivascular; leukocytoclastic vasculitis may exist in new lesions and fibrosis in the older ones. Direct immunofluorescence may demonstrate the presence of $\operatorname{IgG}, \operatorname{IgM}, \operatorname{Ig} A$ and C3 in the dermoepidermal junction and around dermal blood vessels. The disease is usually difficult to treat and has a recurring character, with periods of exacerbation. $^{3}$

\section{CASE REPORT}

Female patient, 58 years old, homemaker, born and from Manaus, had had asymptomatic lesions on the face for 10 years which became more pronounced with solar exposure. The dermatological examination revealed the presence of multiple erythematous-brownish papules of well-defined limits, located on the malar, nasal and frontal regions. Some lesions had telangiectasias on the surface and marked follicular ostia (Figure 1). An histological examination revealed rectified epidermis, with subepidermal Grenz 

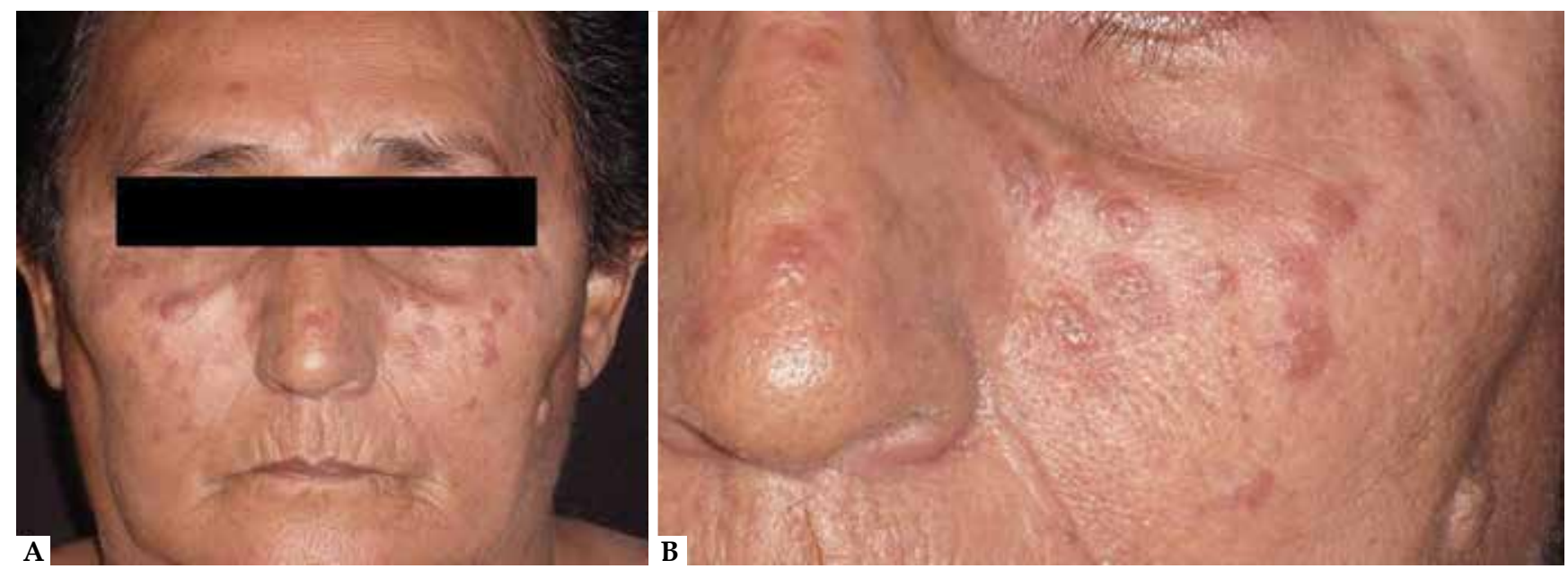

FigURE 1: Erythematous-brownish and asymptomatic, well-delimited papules, some with telangiectasias and marked follicular ostia, located in the malar, nasal and frontal regions
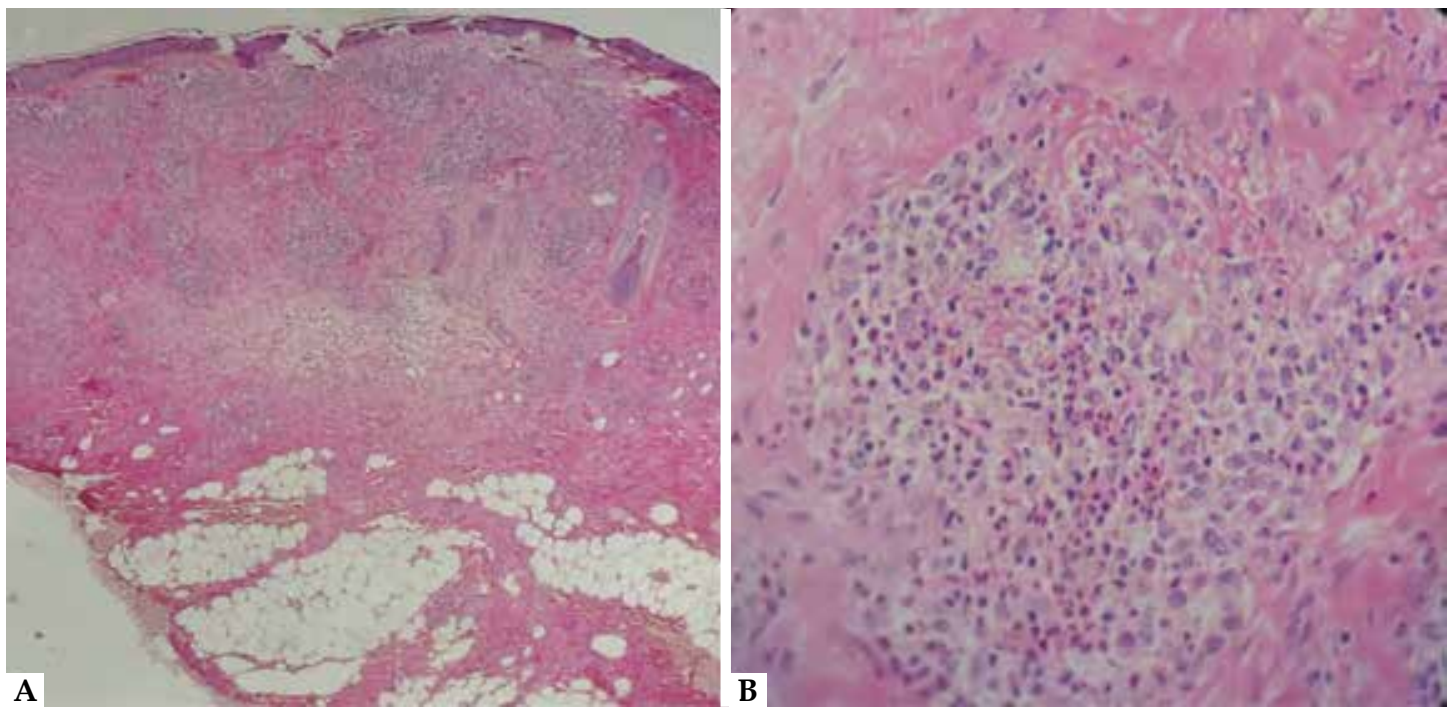

FiguRe 2:

HE 200 e $400 x$

- Rectified

epidermis, with

subepidermal Grenz

zone separating

the nodular dermal

inflammatory

infiltrate, composed

predominantly

of lymphocytes,

histiocytes,

neutrophils

and numerous

eosinophils

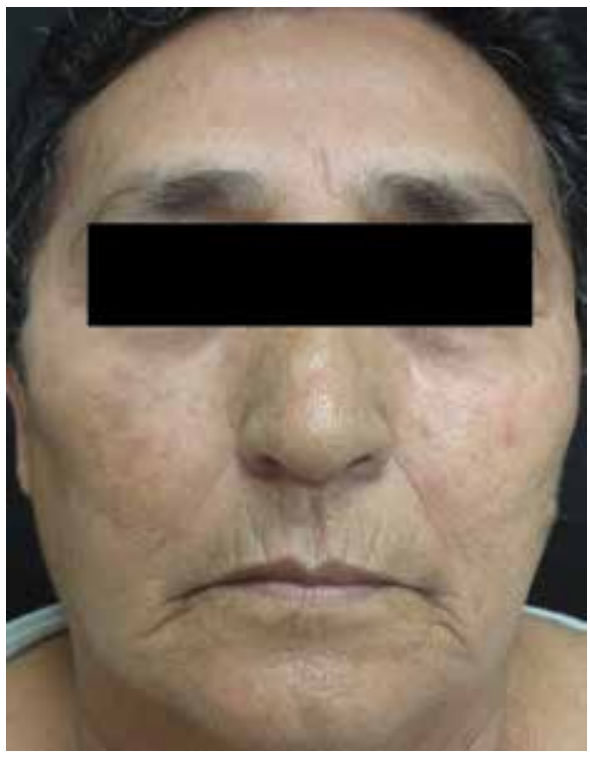

Figure 3:

Lesions resolved

after 4 months

using topical

tacrolimus $0.1 \%$,

evolving with

mild residual

hyperchromia

and a few

telangiectasias

zone separating the nodular dermal inflammatory infiltrate, composed predominantly of lymphocytes, histiocytes, neutrophils and numerous eosinophils (Figure 2). Based on the clinical picture and the histological examination, the granuloma faciale diagnosis was confirmed and treatment was started with two sessions of intralesional corticosteroid infiltration (with a 30-day interval), but response was unsatisfactory. Topical tacrolimus $0.1 \%$ was then introduced, achieving significant improvement in 4 months, with resolution of lesions that progressed with mild residual hyperchromia and a few telangiectasias (Figure 3).

\section{DISCUSSION}

Granuloma faciale was originally described by Wingley in 1945, with the name of eosinophilic granuloma. In 1950, it was individualized as a specific entity, 
differentiated from other cutaneous eosinophilic infiltrates, by Cobane, Lever and Leeper. The term granuloma faciale was adopted only as of 1959 , to avoid confusion with eosinophilic granuloma, from the group of malignant histiocytoses. ${ }^{4}$ Some arguments suggest that GF is a chronic localized form of cutaneous vasculitis, based on the presence of histopathological findings with vasculitis, extravasation of erythrocytes and hemosiderin deposits, and immunohistochemical findings with deposition of immune complexes on the walls of dermal vessels. ${ }^{5}$ There is no systemic involvement nor evidence of abnormal proliferation of the reticuloendothelial system. The lesions are, as a rule, asymptomatic, with a chronic, slowly progressive course and rare spontaneous involution. Although the clinical presentation of GF is usually characteristic, the diagnosis may be delayed by the relative rarity of the disease and the presence of numerous other pathologies that have clinical similarities. ${ }^{6}$ Dermoscopic features may assist in diagnostic suspicion, with the presence of pink-colored background, white lists in different directions and prominent follicular orifices. ${ }^{7}$ Among the main differential diagnoses are the lymphoma and pseudo-lymphoma, sarcoidosis, lupus erythematosus tumidus, polymorphous light eruption, fixed pigmented erythema, erythema elevatum diutinum, foreign body granuloma, granulomatous rosacea. ${ }^{8}$ The disease tends to be refractory to several therapeutic modalities, although there are reports of success with the use of topical and intralesional corticosteroids, antimalarial drugs, dapsone, surgical excision, phototherapy, cryosurgery, dermoabrasion, electrosurgery. More recent studies show good results with the use of topical tacrolimus and some types of laser, such as pulsed dye laser 595nm and KTP 532nm, directed to the prominent vascular component of pathology. ${ }^{9,10}$ The lesions of the patient of the reported case disappeared after four months using topical tacrolimus $0.1 \%$, progressing with mild residual hyperchromia and a few telangiectasias. She continues being periodically monitored, without recurrent lesions.

\section{REFERENCES}

1. Thiyanaratnam J, Doherty SD, Krishnan B, Hsu S. Granuloma faciale: Case report and review. Dermatol Online J. 2009;15:3.

2. Pratap DV, Putta S, Manmohan G, Aruna S, Geethika M. Granuloma faciale with extra-facial involvement. Indian J Dermatol Venereol Leprol. 2010;76:424-6.

3. Ortonne N, Wechsler J, Bagot M, Grosshans E, Cribier B. Granuloma faciale: A clinicopathologic study of 66 patients. J Am Acad Dermatol. 2005;53:1002-9.

4. Nasiri S, Rahimi H, Farnaghi A, Asadi-Kani Z. Granuloma faciale with disseminated extra facial lesions. Dermatol Online J. 2010;16:5.

5. Brandt HR, Arnone M, Valente NY, Sotto MN, Criado PR. Medium and large vessel vasculitis. An Bras Dermatol. 2009;84:55-67.

6. Khaled A, Jones M, Zermani R, Fazaa B, Baccouche $K$, Ben Jilani $S$, et al. Granuloma faciale. Pathologica. 2007;99:306-8.

7. Teixeira DA, Estrozi B, lanhez M. Granuloma faciale: a rare disease from a dermoscopy perspective. An Bras Dermatol. 2013;88:97-100.

8. Requena C, Castejón P, Sanmartín 0, Botella-Estrada R, Nagore E, Serra-Guillén $C$, et al. Rhinophyma-like granuloma faciale. J Eur Acad Dermatol Venereol. 2006;20:881-2.

9. Fikrle T, Pizinger K. Granuloma Faciale Treated with 595-nm Pulsed Dye Laser. Dermatol Surg. 2011;37:102-4.

10. Cecchi R, Pavesi M, Bartoli L, Brunetti L. Topical tacrolimus in the treatment of granuloma faciale. Int J Dermatol. 2010;49:1463-5.

\author{
MAILING ADDRESS: \\ Mônica Santos \\ Av. Codajas, 25 - Cachoeirinha \\ 69065-130 - Manaus - AM \\ Brazil \\ E-mail:m.n.souza.santos@gmail.com
}

How to cite this article: Lima RSA, Maquiné GA, Silva Junior RC, Schettini APM, Santos M. Granuloma faciale: a good therapeutic response with the use of topical tacrolimus. An Bras Dermatol. 2015;90(5):735-7. 